IRA-International Journal of Education \& Multidisciplinary Studies

ISSN 2455-2526; Vol.12, Issue 03 (September, 2018)

Pg. no. 74-86.

Institute of Research Advances

http://research-advances.org/index.php/IJEMS

\title{
Using Computer Technology in the ESL Writing Class
}

\author{
Noor Zainab Abdul Razak ${ }^{1 \#}$, Amira Syafiqah Ameruddin ${ }^{2} \&$ Nur Hazirah Che Ithnin ${ }^{3}$ \\ 1,2,3 Universiti Teknologi Malaysia, Johor, Malaysia. \\ \#corresponding author. \\ Type of Review: Peer Reviewed. \\ DOl: http://dx.doi.org/10.21013/jems.v12.n3.p3

How to cite this paper:
Razak, N.Z.A., Amerruddin, A.S., Ithnin, N.H.C. (2018). Using Computer Technology in the ESL Writing
Class. IRA International Journal of Education and Multidisciplinary Studies (ISSN 2455-2526), 12(3), 74-
86.doi: http://dx.doi.org/10.21013/jems.V12.n3.p3

(c) Institute of Research Advances.

\section{(cc) BY-NC}

This work is licensed under a Creative Commons Attribution-Non Commercial 4.0 International License subject to proper citation to the publication source of the work.

Disclaimer: The scholarly papers as reviewed and published by the Institute of Research Advances (IRA) are the views and opinions of their respective authors and are not the views or opinions of the IRA. The IRA disclaims of any harm or loss caused due to the published content to any party.

Institute of Research Advances is an institutional publisher member of Publishers Inter Linking Association Inc. (PILA-CrossRef), USA. The institute is an institutional signatory to the Budapest Open Access Initiative, Hungary advocating the open access of scientific and scholarly knowledge. The Institute is a registered content provider under Open Access Initiative Protocol for Metadata Harvesting (OAI-PMH).

The journal is indexed \& included in WorldCat Discovery Service (USA), CrossRef Metadata Search (USA), WorldCat (USA), OCLC (USA), Open J-Gate (India), EZB (Germany) Scilit (Switzerland), Airiti (China), Bielefeld Academic Search Engine (BASE) of Bielefeld University, Germany, PKP Index of Simon Fraser University, Canada. 


\begin{abstract}
Using computer and the Internet allow students and teachers to interact with one another with no boundaries and this affects the students' attitude and their motivation in learning. This study focuses on the attitude, motivation and performances of ESL learners in learning writing using Google Docs. The quantitative instruments consisted of questionnaire, pre-test, and post-test while the qualitative instruments consisted of interview recordings and the treatment sessions. The results from the questionnaire were used to identify the attitude and motivation of the students while the results from the pre-test and post-test were used to determine the students' performances after the use of Google Docs. The result of the study showed that the students had positive attitude toward the use of Google Docs in learning and were also motivated to learn. Google Docs manage to encourage them to write better, and there were improvements in learners' performances. They were able to generate more ideas and organized their writing accordingly. As a conclusion, Google Docs should be implemented by teachers to teach process writing as the tool can motivate the students to learn better.
\end{abstract}

Keywords: Attitude, Google Docs, motivation, performance, process writing, writing skill

\title{
Introduction
}

The growth of technological instruments and globalization contribute to the creative and innovative development in many fields and areas especially in the field of education. Technology is continuously evolving and this situation allows the incorporation of interactive learning environment in language classroom to fulfil the needs of the 21st century students (Deter, Cuthrell\&Stapleston, 2010). Due to this circumstance, this research applied the integration of Computer-Supported Collaborative Writing through the use of Web 2.0 tools which allows users to socially connect, interact, and switch information between one another (Bragg, 2007).

This research aims to encourage students' writing skill through the use of Google Docs. Therefore, the focus should be given to the atmosphere of writing lessons among ESL learners as pupils need to undergo several examinations throughout the primary and secondary school. In addition, most tests contain writing components and students need to have good writing skills to do well in examinations. In other words, learning to write and acquiring writing skills can be considered as an important foundation in a child's development and can pave the way for academic success in the future.

Nagin (2003) states that writing is challenging because there are various uncertainties involved in the process of writing. The writer doesnot always know beforehand where to begin, much less how to proceed. This demonstrates that writing is a complex process. Therefore, it is of perennial interest for English language teachers to become aware of this matter and find ways in developing and improving students' writing.

In addition, al-Buainain (2006) emphasized that writing can be regarded as one of the toughest and exasperating aspect of language skills to be taught in ESL or EFL classroom. According to Winkler and McCuen (1997) students possess negative assumptions and interpretation towards writing as they believed that writing must consist of long sentences, and detail focus needs to be given to punctuation and grammar which make it more difficult for them to write perfectly. Therefore, Google Docs is presented as a mean to improvise teaching pedagogy that teachers usually apply in their classroom. This research also hoped to shed some lights on more interactive writing platform and activities which promote collaborative learning among ESL learners in Malaysia.

The purpose of this study is to investigate the students' attitude, motivation and performances towards the use of Google Docs in the classroom to learn process writing. As far as it is concerned, there is no current research on the use of Google Docs in teaching process writing in ESL classrooms specifically. Hence, this study is aimed to discover the potential use of Google Docs to be implemented in ESL classrooms in Malaysia to teach process writing.

\section{Conceptual Framework}

The present study is grounded based on Vygotsky (1978) social cognitive theory which highlights the importance of social interactions between students through a specific mediated learning process. The mediated 
learning experience means the necessity to have other party to channel and share knowledge so that it can be understood by all participants within the group (Ashman \& Gillies, 2003). William and Burden (1997) elaborated further that in developing learners' skills and knowledge, assistance and communication between less proficient students with more capable users are necessary. Hence, it is important to emphasize that learner centred learning leads to better non-threatening learning environment where students can possibly acquire more second language input through peer feedback and guidance.

Human can act as the mediator or platform for successful language learning (Vygotsky, 1978). Specifically, this situation elaborates the notion of scaffolding in the second language lessons. Scaffolding aids ESL learners who face difficulties in mastering some language concepts to gain peer advices through recruiting in assignment, task simplification, maintaining the learning goal, motivating each other to overcome frustration during task completion, and planning the arrangement of ideas throughout the learning process (Wood, Bruner, \& Ross, 1976). Therefore, incapable learners will be able to internalize the language knowledge they acquired through more competent friends. Whereas, the high proficient learners will be able to strengthen the second language input through the cooperation with other learners in the collaborative-based assignments.

In this research, the researchers applied a framework adapted from $\mathrm{Li}$, Chu, $\mathrm{Ki}$ and Woo (2012) on collaborative writing through Google Docs. Firstly, a Google Docs based collaborative writing platforms are set up by using an online collaborative writing medium. Through these means, the respondents of different language proficiency cooperate with each other to complete several writing tasks together. The writing tasks were done through the Google Docs-based collaborative writing which was guided and instructed by the researchers in each session. Meanwhile, students facilitated and communicated collaboratively to complete essays in every task. It is crucial to stress that all interactions either student-student or teacher-student occurred in this study were done through online medium.

The present study applied all the stages need to be undergone by the students in collaborative writing process which includes group pre-writing, drafting, revising and editing that were done during the treatment session within two weeks. In the prewriting stage of collaborative writing, students brainstormed the ideas on what they will be writing. Then, the drafting stage needed the students to collaboratively expand and elaborate their ideas in depth. Plus, this stage focused on the organization and expansion of ideas instead of grammatical structure. The next stage of revising comprises of three elements which are re-read, re-organized and revise based on comments of the essay that have been written on the Google Docs by correcting minor changes on the word choice or sentence structure. As for the last stage of editing, all students had to put the writing in the final form by looking closely at the linguistic and content correctness in their essay. Only then, the essay can be published as the final product for each session during the treatment. The description of each stage in the collaborative writing process is based on Tompkins (2008). Therefore, through these stages, students are expected to master their writing skill better after going through the Google Docs-based collaborative writing in this particular study.

\section{The relationship of Google Docs based process writing with Vygotsky (1978) constructivism theory}

In writing aspect, constructivism theory involves collaborative learning where students need to participate and communicate with each other and this shows that knowledge is developed with individuals of the same groups and shared similar norms and belief (Hewett, 2009). Therefore, the researchers adapt this theory in designing the platform of Google Docs based collaborative writing. First, the researchers select the respondents based on their proficiency level, which are students of high proficiency level in English and students of low proficiency in the language. Students' proficiency level was determined based on their Form 1 end year examination result. It is important to emphasize that the variation in language proficiency encourages scaffolding among learners which meet the aim of applying constructivist model and having collaborative writing tasks. The framework for this study supports the application of social constructivist theory where Google Docs based writing atmosphere is conducted in the collaborative context.

Based on Witts (2011), Google Docs permits users to exchange ideas, opinion and thoughts as well as revising content and comments based on their knowledge through online interaction. Besides, in collaborative writing, students need to undergo several stages which are prewriting, drafting, revising, editing, and publishing (Li, Chu, Ki \& Woo, 2012). Therefore, this is the part where the social constructivist theory is implemented in the study. 
Moreover, the theory highlights that knowledge acquisition is the product of social interaction. In this study, students of different proficiency level worked collaboratively to complete writing task in a particular Google Docs webpage provided for them. Therefore, interaction and communication existed between the respondents through the act of revising, commenting, and editing each other's work. The implementation of Google Docs-based writing lesson will provide better learning environment where students are actively participate in conducting discussions. Furthermore, online interaction and communication encourage successful negotiation medium between students (Almala, 2006).

With reference to $\mathrm{Li}$, Chu, $\mathrm{Ki}$ and Woo (2012), the Google Docs-based writing environment and collaborative writing process is supported by the social view of writing process (Faigley, 1986; Tompkins, 2008). According to Faigley (1986) the social perspective of writing process is common in the collaborative writing pedagogy as the central view of this theory is writing. This is supported by Tompkins (2008) who proposes that collaborative writing is closely related to the social view of writing because the process of writing represents students' thoughts which consists of pre-writing, drafting, revising, editing, and publishing phases.Therefore, by implementing the use of Google Docs-based collaborative writing in English language classroom, the present research will develop ESL learners' interest and performance in writing through the use of Google Docs in English language lesson. This is good as students are more prepared and ready for independent writing after they have gone through the processes involved in collaborative writing through Google Docs (Tompkins, 2008).

\section{Integrating the use of Google Docs in ESL writing classroom}

Nazatulshima (2006) stated that the use of computer technology is developing due to the increasing number of software created for educational purposes.In addition, Judd, Kennedy and Cropper (2010) mention that Google Docs is getting more and more popular among students and teachers in the education atmosphere. Basically it acts as collaborative writing equipment which encourages self-learning and achievement among the students. Since Google Docs is one of the web 2.0 tools, it has been enlisted as the current trend which incorporated language lesson to enhance the process of learning and teaching (Hughes, 2009). Not only that, Bower, Woo, Roberts and Watters (2006) as well as Bruns and Humphreys (2007) suggest that, Google Docs is particularly popular and it serves as an interactive website that can be edited, reviewed and revised by several people through the use of some user-friendly page tools. Due to this circumstance, the concept of Google Docs is surprisingly applicable towards the language classroom context as it provides variation in terms of teaching material introduced by the teacher. Besides, Arronson (2002) adds that Google Docsis also a base for E-learning which supports collaborative learning experience among students. In short, this is the feature which makes Google Docs more fascinating to be applied in writing classroom (Arronson, 2002; and Leuf\& Cunningham, 2004).

It is important to emphasize that the use of Google Docs certainly encourages collaborative learning among students. This is because Google Docs is designed to be utilized by more than one person, and each individual will help each other in the revising process to expand the content by providing information, attaching files or documents, or creating links to enhance understanding of each student on certain topic (Morgan \& Smith, 2008). Thus collaboration among students whether they are of high or lower proficiency in the language exists within interaction and communication through Google Docs. Therefore through the collaborative feature that Google Docs serves, it is expected that supportive learning among students can be encouraged and this will help them to improve their writing skills especially to produce better essays.

Other than that, Google Docs can also be used upon the wide range of the second language learner to develop their language acquisition. Although it seems a bit sophisticated, the process of language learning can be applied to all students of different proficiency in the language. Besides, Robinson (2006) suggests that Google Docs is an effective tool for teachers and educatorsbecause it allows users to quickly update the content of the webpage which make it more fascinating. Specifically, this research highlights Google Docs as a platform to build up collaborative interaction which allows users to facilitate each other in learning to write. The evidence from the research findings shows that Google Docs provides the best medium to support online collaborative learning and teaching experience for both teachers and students. Besides, this research discovered that, Google Docs helps learners to undergo metacognitive task as well as activities which help to enhance language learning. A research with 59 standard four students in China practiced the approach of Google Docs-based collaborative writing as a platform to encourage students' writing skill ( $\mathrm{Li}, \mathrm{Chu}, \mathrm{Ki} \&$ Woo, 2012). In addition, the study was conducted to 
measure students' performance, and motivation towards using Google Docs as a method to teach writing lesson. The Google Docs that has been set is given a name of Joyous Writing Club (JWC) which has been developed by online Google Docs software which is Media Google Docs. Basically, the research instruments for this study are observation, questionnaire, interviews and reflection. The results of this study illustrate positive effects of using Google Docs in language classroom as it encourages motivation in writing, interaction and writing performance.

The next research that has been reviewed by the researchers was by Deter et al. (2010). In this research, the emphasis was given to the use of Web 2.0 tools especially Google Docs as one of the new methods to be brought in the classroom environment. This study involved 40 students of social study course and the focus was on students' perception towards the use of Google Docs in online instruction and its potential to be used in the classroom environment. The data for this research was collected by using surveys and written reflection. Although there were some conflicts while conducting the Google Docs-based learning in the study, the overall perception among students was encouraging and positive. It can be described that, in previous studies Google Docs serves as the best platform of learning to write in English due to its feature which allows collaborative writing among learners. Besides, it can also be said that Google Docs helps to produce non-threatening classroom experience.

\section{Participants of the Study}

This research involves purposive sampling where participants were selected from a government aided secondary school. Specifically, nine respondents from a Form 2 class were chosen to participate in this research. All of the participants were 14 years old and they were chosen because of their proficiency in using the language and their ability to voice out their opinion in the lesson. Since this research focuses on using Google Docs as writing tool, it is important to insert the elements of collaborative learning among students. Therefore, the researchers had decided on using 3 participants for each proficiency level, namely high proficiency, intermediate and low proficient. The students' level of proficiency was categorized based on their grades in the Form 1 final English language examination. Specifically, participants who got ' $A$ ' grade is categorized as high proficiency participants, those who got ' $\mathrm{B}$ ' grade is intermediate level, while participants with ' $\mathrm{C}$ ' grade fell under low proficient category. Through this way the pattern of the social constructivist theory in collaborative writing can be clearly seen. Most of all by selecting these particular participants, the effect of using Google Docs to improve ESL learners' writing skill can be measured by looking at the students' performance after the treatment.

\section{Research Procedure}

This research started with a pre-test where participants were asked to write an essay to be assessed. The aim of this pre-test was to identify students' performance of their essay writing before they underwent the treatment sessions. During the treatment sessions, participants used Google Docs as a mean for collaborative writing to have an interactive writing lesson experience which serves as a platform to collaborate and prepare them with better writing skill. Participants spent eight hours, which were divided into four sessions participating in the collaborative writing during the treatment session. Later, all the participants had to attend a post-test as to again identify their performances in their essay writing. During the first time of meeting, the researchers provided the students with the login IDs (email address) and password to set up their own email address that were used as identification to join the Google Docs website. It is needed to be emphasized here that providing the respondents with Google Docs IDs is significant to reduce the hassle faced by both respondents and researchers in terms of time and technological related problems. Since the website is in private mode, students will not be able to view the content unless they are added as the member of the group. Next, the Google Docs platforms were set up for them by registering each student according to small Google Docs group of three. The researchers used Google Docs webpage to serve as the medium to encourage students writing skill and to introduce the collaborative writing experience among students. After signing in as the main administer to the web, the researchers created several pages as a channel to deliver messages, information, interaction and instructions to the students. Specific name, task, and week number were written in each page in the website to make it more user-friendly. After that, an ice-breaking session was done between the researchers and the students by usingGoogle Docs to familiarize themselves to the tools and application that can be integrated in the Google Docs pages. Thus, as they are familiar with the interface and layout of the Google Docs, the flow of the treatments will not be interrupted due to several technical difficulties. 


\section{Writing assessment (Pre-Test and Post-Test)}

The writing assessments which are the pre-test and post-test were carried out to examine the effect of using Google Docs towards the participants' performance in writing, specifically essay composition. Basically, students have undergone pre-test and post-test which required them to write descriptive essays on topics which have been selected by the researchers. The topics selected for the tests are based on the curriculum specification provided by the Ministry of Education for Form 2 students as the participants selected were all from the government aided school. Then, the essays were evaluated by an experienced secondary school teacher using a rubric which is designed as marking guidelines for government aided school. The rubric guidelines were prepared by the Malaysian Examination Syndicate (MES) and approved by the Ministry of Education (MOE). By this way, the validity and reliability of the assessments' scores can be assured.

\section{The implementation of Google Docs for collaborative writing}

In particular, the treatment duration was two weeks. Two sessions of Google Docs-based collaborative writing activities were conducted in each week where the lengths are approximately two hours per session. Thus, the total of 8 hours treatment was given to prepare the students with appropriate knowledge to develop their writing skill via the implementation of Google Docs. Each treatment session requires the students to undergo different writing activities which need them to collaborate with each other in completing certain tasks.

In the first session, the researchers introduced the students with simple and compound types of sentence based on the curriculum specification of Form 2. The steps of constructing sentences by following the rules of subject-verb-agreement were also highlighted. Since the students are already in Form 2, it is expected that they already have background knowledge about sentence types and structure. Thus, students were given some practices to strengthen their ability in constructing sentences. As the treatment sessions over, students took a post-test in the fifth week. Once again they need to write an essay individually. The post-test question was the same as the pre-test and the time allocated to finish the essay is one hour with the word count should be more than 120 words, based on the PMR standard. Later, the pre and post-test essays of the students were evaluated by experienced teacher who has been teaching for 7 years at secondary school and the evaluation is according to rubric by Malaysian Examination Syndicate (MES).

Since Google Docs deals with the aspect of collaborative writing, students worked collaboratively to complete the tasks given through prewriting, drafting, revising process, and the final touch is editing the essay. In this part, students are expected to provide peer feedbacks through comments or during online interaction by correcting errors and mistakes on the elements of sentence structure. Nevertheless, students are encouraged to revise on other relevant linguistic components as well. As Google Docs allows users to edit and revise each other's contribution in the webpage, students of high proficiency were expected to facilitate low proficient students by providing comments and advice on the errors found in the essays. In a way, learner centred learning and scaffolding among students can be created.

\section{Data Analysis}

The analysis of data for writing assessment was based on the marks scored by each respondent before and after the treatment. The researchers have analyzed the respondents' essays in both tests, and compared them in terms of students' sentence structure focusing on the rules of SVA. The respondents consist of mainly female students with $66.6 \%$ while the remaining $33.3 \%$ are male respondents. Generally, Malay students represent about $44.4 \%$ from the total number of respondents, followed by Chinese students with $33.3 \%$ and the remaining $22.2 \%$ represents the Indian respondents.

Since this research is to examine whether Computer-Supported Collaborative Writing works among ESL learners, the researchers had selected samples of sentences from respondents' essays in pre-testand post-test to examine the differences. The researchers choose sentences of the same ideas so that the pattern of sentence construction can be easily identified. In particular, the focus of this study is only on Subject-Verb-Agreement (SVA). Table 1 below summarizes the respondents' achievements in both pre-test and post-test. 
Table 1: The comparison of achievement in the pre-test as well as post-test for each respondent

\begin{tabular}{|c|c|c|c|c|}
\hline Google Docs group & $\begin{array}{c}\text { Stude } \\
\text { nt }\end{array}$ & $\begin{array}{c}\text { Students' Proficiency } \\
\text { Level }\end{array}$ & $\begin{array}{c}\text { Pre-test } \\
\text { scores }\end{array}$ & $\begin{array}{c}\text { Post-test } \\
\text { scores }\end{array}$ \\
\hline \multirow{3}{*}{1} & A & High & 18 & 22 \\
\cline { 2 - 5 } & B & Intermediate & 14 & 18 \\
\cline { 2 - 5 } & C & Low & 9 & 12 \\
\hline \multirow{3}{*}{2} & D & High & 20 & 23 \\
\cline { 2 - 5 } & E & Intermediate & 16 & 20 \\
\cline { 2 - 5 } & F & Low & 10 & 13 \\
\hline \multirow{3}{*}{3} & G & High & 19 & 23 \\
\cline { 2 - 5 } & H & Intermediate & 15 & 19 \\
\cline { 2 - 5 } & I & Low & 11 & 15 \\
\hline
\end{tabular}

Table 2 shows all participants in this research had positive improvements in their writing score after the treatments with an increment of the score ranges between 3 to 4 points. Basically, all of the respondents began to understand the concept of SVA where they produced sentences with appropriate grammar structure and forms. Based on respondents A, D and G, the students can be regarded as having full understanding on how to use correct SVA rules in the composition after the treatment. The following samples of students' sentence production were extracted from their pre-test and post-test essay.

Table 2: Students' sentence production from pre-test and post-test essay

\begin{tabular}{|r|l|l|}
\hline $\begin{array}{c}\text { Respond } \\
\text { ent }\end{array}$ & \multicolumn{1}{|c|}{ Pre-test } & \multicolumn{1}{|c|}{ Post-test } \\
\hline A & $\begin{array}{l}\text { During my school holidays, my father decideto } \\
\text { bring us to have a picnic in Pantai Port Dickson. }\end{array}$ & $\begin{array}{l}\text { On last week Sunday, my father brought all of } \\
\text { the family members to go out for picnic in } \\
\text { GunungLedang, Johor. }\end{array}$ \\
\hline D & $\begin{array}{l}\text { The accident tell me about we mustcautions when } \\
\text { we are driving on the road or... }\end{array}$ & $\begin{array}{l}\text { The scary and horrible accident reminded me } \\
\text { that we need to be careful and fresh if we want to } \\
\text { drive our car using the highways. }\end{array}$ \\
\hline G & $\begin{array}{l}\text { Last week, I am so happy as well as excited } \\
\text { during the journey to Pantai Klebang because I } \\
\text { like to spend free time with family and friends. }\end{array}$ & $\begin{array}{l}\text { I was so cheerful and enjoy my trip to Melaka } \\
\text { during the school break two weeks ago. }\end{array}$ \\
\hline
\end{tabular}

It can be said that respondents $\mathrm{A}, \mathrm{D}$, and $\mathrm{G}$ possess wide range of vocabulary where he or she can shift the words used according to the suitability in the sentence context. This means that, they do not have to stick around with the same word to express the content of writing and to develop ideas. Plus, all the three of them are categorized as students with excellent proficiency in English language and they have more input on the second language compared to other respondents. Indirectly, this shows that the use of Google Docs enriches their understanding and develops better writing skills among them since the students are helping each other in rectifying errors and mistakes (Cress \&Kimmerle, 2008).

Since this research concerns on the main feature of Google Docs which promotes collaborative writing, it can be said that, most of the respondents and teachers mutually benefit from it. This is because advance students, intermediate and low proficient students exhibit affirmative development in writing. Particularly, respondents B, C, $\mathrm{E}$ and $\mathrm{F}$ simplified their sentence structure which makes the meanings of the sentences clearer and comprehensible by the readers. Consider the following sentences derived from the students' essay: 
Table 3: Pre-test and post-test sentence production

\begin{tabular}{|r|l|l|}
\hline \multicolumn{1}{|c|}{$\begin{array}{l}\text { Respond } \\
\text { ent }\end{array}$} & \multicolumn{1}{|c|}{ Pre-test } & \multicolumn{1}{|c|}{ Post-test } \\
\hline B & $\begin{array}{l}\text { On Previous Monday, my uncle and I want to went to } \\
\text { Kuala Lumpur to visit my grandfather }\end{array}$ & $\begin{array}{l}\text { Last week, my family and I went to the } \\
\text { zoo in Johor Bahru. }\end{array}$ \\
\hline C & $\begin{array}{l}\text { Last Sunday, auntie Tina and uncle Ridhuan bring me to } \\
\text { shopping at the Pasaraya Sakan in Segamat area. }\end{array}$ & $\begin{array}{l}\text { During the school holiday, my uncle } \\
\text { brought me to go to Batu Pahat city. }\end{array}$ \\
\hline E & $\begin{array}{l}\text { We got out from the car and went to see what had } \\
\text { happening across the road. }\end{array}$ & $\begin{array}{l}\text { All of us looked at the accident from the } \\
\text { window in our car. }\end{array}$ \\
\hline F & $\begin{array}{l}\text { Last week Saturday, there is an accident were helding on } \\
\text { North South highway at 2.30 PM. }\end{array}$ & $\begin{array}{l}\text { In school holiday, there was accident } \\
\text { happening on North South Highway. }\end{array}$ \\
\hline
\end{tabular}

Based on the excerpts of the respondents' sample of sentences, the grammatical rule of SVA that they used is accurate. Thus, through all the treatments given to the respondents through Google Docs mediated collaborative learning, students developed peer feedback, scaffolding and independent learning which results in better awareness of constructing grammatical sentences and essays (O’Neill, 2005).

In particular, the researchers would say that student $\mathrm{H}$ shows great improvements in producing better essay and creating good sentences. Basically, he comes out with meaningful and a good written discourse specifically on the use of SVA. Furthermore, the respondents do not stick with his previous sentence but rather, he comes out with new lexical choice with the correct selection of tenses according to the essay's context. As for reference, consider the following sentences by Respondent $\mathrm{H}$ :

Pre-test $\quad:$ I will also reminded my relatives be more careful when use highway.

Post-test : I advised my friends, family and relatives so that they will be caution when they use the highway.

By looking closely, this situation reflects on the factors which affect students' performance in writing. The students' achievements can be seen developed by different ways or perspectives. In this case, the researchers found that, computer-supported collaborative writing such as Google Docs does work among the ESL participants in stimulating interest in learning to write better essays and somehow it boosts up their accomplishment in language classroom.

In general, it can be said that all respondents in this study showed positive improvements in their post-test. The respondents were able to generate more ideas in their writing and overcame some of their grammatical errors. They were also able to create more sentences to support their main idea. This gave them more marks in terms of content. The students were able to write better and this tallied with the findings whereby the respondents feel they could write better with the use of Google Docs. The peer-review and the collaboration helped the students to notice the mistakes they were doing and made them more conscious of their writing.

\section{Attitude toward the Use of Google Docs in Learning Writing}

One of the aims of this study is to discover the attitude of the respondents using Google Docs as a platform to learn process writing. Questionnaire was distributed at the end of the session to examine the respondent's attitude towards using Google Docs to learn process writing. The findings obtained from this study shows that the respondents had positive attitude towards the use of Google Docs in completing their tasks. $75 \%$ of the respondents felt that Google Docs was interesting and fun and most of them agreed that they like the use of Google Docs in learning process writing. More than half of the respondents (62.5\%) felt that Google Docs was useful when learning process writing. This could be because the advanced features of the Google Docs which allow users to simultaneously edit the document together while at the same time a chat box also allows users to communicate in the real time. Therefore, the respondents were able to carry out the process writing continuously without disturbance. This made the flow of learning smooth and could contribute to the positive attitude that the students have toward the use of Google Docs. 
Based on the interview sessions done with three respondents, all of them found that using Google Docs made it interesting because they were able to chat and discuss with their friends, which encouraged them to continue writing. Since they have experience in using Microsoft Words, they were familiar to the tools in Google Docs and this made them comfortable to use the tool. Process writing itself has the ability to promote communication among students and the students found it interesting and encouraging continuing writing, while, chat box enables students to develop positive attitude toward the tool. Besides that, familiarity with the tool is important and affects the respondents' attitude toward it. When the respondents started to get used to the tools in Google Docs, they were more comfortable. Thus, the use of Google Docs can help build a positive environment for the students to learn better.

More than half of the respondents agreed and 12.5 percent of the respondents strongly agree that Google Docs was effective in learning process writing. The respondents found Google Docs was useful, and effective. One out of three interviewees mentioned that she preferred having the discussion online where she can see all her friends work and immediately give responses and answers to the question asked. She also said that Google Docs gave them more opportunity to communicate with one another. From this response, it can be concluded that communication during process writing is essential.

However, there were several students who had negative attitude towards the integration of Google Docs in their learning process. There were 25 percent of the respondents who felt that Google Docs was not useful. One out of three respondents said she did not quite like the use of Google Docs because she had trouble with the Internet connection and that affected her attention and participation during the treatment sessions. From this situation, it can be said that any form of disturbance affects the respondents' attitude toward using the tool. 37.5 percent of the respondents felt that Google Docs was not easy to handle. One out of three respondents mentioned that she had trouble understanding how to manage the tools in Google Docs such as the comment button. She had a hard time adjusting to the interface and understanding the features of Google Docs. These were some of the problems that made the respondents uninterested and had negative attitude towards the use of Google Docs. Therefore, the respondents develop negative attitude towards the tool.

Most of the respondentsthat is about 87.5 percent favored Google Docs because of the fast feedback they received. Two out of three interviewees mentioned that they enjoyed the interaction between their peers when writing. They both said that the comments gave them more opportunity to learn more from their mistakes. Overall, the students had positive attitude toward the implementation of Google Docs in learning process writing and they also gained more knowledge in process writing. Respondents were also given more authority in their own learning process.

50 percent of the respondents agree that they felt more interested in the topic being taught when Google Docs was used, but another half disagreed to the statement. This could be because the tool did not have significant effect toward the respondents. Two out of three respondents said that they got more interested to learn writing when Google Docs is used because they could participate actively. Since being in the virtual world does not require a faceto-face communication, some students may benefit from it, as they do not have to be shy or scared to participate in classroom activities. 75 percent of the students felt that they could write better when using Google Docs. Three interviewees said they could improve their writing skills, as they knew what their mistakes were. They felt positive towards their own writing and did not feel offended when their friends pointed out their mistakes as they took it as a learning process.

\section{Students' Motivation toward the Use of Google Docs in Learning Writing}

The second objective of this study is to identify the students' motivation when using Google Docs to learn process writing. 75 percent of the respondents felt motivated, and look forward to the use of Google Docs to learn process writing while the other 25 percent did not feel motivated nor look forward to the use of it in class. One out of three interviewees mentioned that she preferred to use Google Docs compared to the traditional pen and paper because it is more convenient in terms of correcting the mistakes. This is an advantage of using the technology. Instead of having to write all over again after being corrected, the students can just edit their work without having to go through a lot of fuss. This gives motivation to the students, as they do not have to write all over again. 
Seven out of eight of the respondents felt they could do process writing together without having the teacher around. This could be because the role of the teacher is just as the facilitator. The teacher should not be involved in the discussions, but the teacher should be guiding the students throughout the whole learning process. However, the teacher's role is the most important at the beginning of the task, especially during explaining the task. Three interviewees said they felt motivated to do the task. One of the main reasons was that they felt comfortable being in a group of people they are familiar with. They did not feel inferior or ashamed to admit their mistakes or to argue about it. This shows that the students were comfortable and confident with their peers. They managed to accept the comments and corrected their mistakes.

However, there was a respondent who said that he felt uncomfortable having his work being commented. He admitted that the comments made him write better, but he did not feel comfortable having his writing judged by his peers. Another respondent claimed that she was scared to receive the comments and suggestion because it made her feel like her work was not good enough. But she also said that she felt motivated to do the task because she knew she had to be better. This situation happened most probably because the respondents were insecure of their writing. This would affect their motivation, as they would feel like they are less than their peers.

In addition to that, 50 percent of the respondents felt that they do not need Google Docs in order to feel motivated to learn writing. They felt that Google Docs did not affect them much in learning process writing. This can also explain the reason why 65 percent of the respondents will not be using Google Docs outside of the class. One of the respondents mentioned that she liked how the Google Docs works by letting them interact together, but other problems such as the Internet and timing were a bit frustrating. Therefore, she would not be using it unless it is used by the teacher for teaching and learning purposes.

75 percent of the respondents felt that they need Google Docs to learn process writing. One out of three interviewees said that Google Docs makes process writing quicker. Since all the users are using the tool together, they can view the same thing together and do not have to take turn to review a work. As mentioned earlier, the respondents do not have to rewrite the whole essay again as they can just edit it and this saves a lot of time.

\section{Conclusion}

The present study aimed to examine whether Computer-Supported Collaborative Writing works among ESL learners, specifically to investigate the effect of using Google Docs based collaborative writing towards ESL learners' writing performance. Specifically, the respondents indicate positive increment of essay scores in the posttest where the range of increased marks is between 3 to 4 points. Obviously, Google Docs leads to the development of students' ability in essay writing since the marks allocated represent the whole components of essay organization by the Malaysian Examination Syndicate writing rubrics which consist of ideas development, sentence structure, mechanics, and essay organization. The second research question for this study is answered as Google Docs provide a medium of scaffolding which helps learners to acquire better performance in writing essays. Moreover, Ryan (2007) has also proposed that integrating online collaborating learning tools support and build students' achievement in language classroom.

Based on the findings, it can also be said that students are not only improving in terms of their performance in essay writing. It is proven as there is a slight development in the way they construct sentences through appropriate use of SVA rules. The aspect of sentence structure gives impact towards students' writing performance. Thus it is suggested to provide students with explicit linguistic form and functions in writing to help them to better understand the language rules. This agrees with Kim et al. (2009) and Trentin (2009) who proposed that collaborative writing through Google Docs provides chances for students to develop academic writing ability.

As for the last challenge related to the collaborative feature of Google Docs is about the respondents' contribution throughout the treatments. Since, the researchers play role as the main administrator of all the Google Docs websites used by the students for collaborative writing, all respondents' activities from the beginning to the end can be easily monitored. According to the Google Docs login each website, the respondents, regardless of their proficiency level, are fond of revising their Google Docs with non-language related contribution. Generally, this includes revising the fond size, uploading pictures, changing the Google Docs background and other activities to get their Google Docs appear beautiful and creative compared to other groups. However, language related contribution 
such as editing the sentence structure, revising appropriate synonyms or vocabulary, and rectifying grammar errors are not frequently done by the students. In the researchers' point of view, students should be encouraged to revise and edit certain linguistics aspects which they think appropriate to show that they understand on how the language forms and functions work. In addition, revising the linguistic aspect will also help them to perform better in acquiring the second language. Since the present study is a small scale research done on 9 ESL of a secondary school, the findings cannot be generalized to other second language classroom. Small sample size also restricts interactions and the learning process might be in a very minimal level (Violet \& Mansfield, 2006). The second limitation of the research is on the aspect of time constraint. In particular, the treatment sessions that have been conducted among the students are very short. In order to get an appropriate measurement of students' performance, longer treatment process is required so that students are mentally and physically prepared for writing assessments. Then, it can be said that although all respondents are IT savvy and familiar enough with the use of computer, bringing the ICT tools in the classroom can also be devastating for the students since they are not very familiar with this kind of learning environment. Therefore, they might be anxious with the learning process as it is totally different with the conventional classroom atmosphere.

From this study, it can be seen that the use of Google Docs has positive effect towards the students' attitude, motivation and performances. The students favored the use of technology and they felt interested in learning writing through the use of the tool. Thus, it is important to encourage teachers to apply technology-based tasks to enhance students' motivation and change their attitude towards learning English language, at the same time improving their writing skills. This study could also provide insights on the implementation of using Google Docs and its' implications towards students' motivation and attitude in learning to write in ESL classrooms. Furthermore, this study aims to prove that learning process writing using Google Docs can be a tool for teachers to conduct more effective lessons on writing.

\section{Pedagogical implications}

Using Google Docs has helped teachers to create independents classroom learning environment. Thus, the teachers' responsibility is to encourage the students to do some editing and revising process by providing peer feedbacks and scaffolding which will lead to better teaching and learning environment. Nevertheless, teachers need to be aware of the learning process by monitoring each feedback and comments among the students so that there will not be any misunderstanding or misconceptions on the language forms and structure during the scaffolding process (Scardamalia\&Bereiter, 2006). In addition, Leung and Chu (2009) have also highlighted that teachers should play active roles during the E-learning session to avoid the students from doing last minute work which will inhibit the acquisition of language skills.

Other than that, it will be very beneficial if teachers can encourage the students to write collaboratively during the learning process. In a way, collaborative writing allows the students to be more critical and analytical where they have to think of the way how to generate ideas and link it together based on different people opinion. Finally, it is good to clarify that, the use of Google Docs should be implemented in the language classroom as it provides new insights for both teachers and students to a more resourceful and authentic learning materials and approaches which are totally different with the traditional classroom practices. In particular, providing genuine collaborative classroom environment enhances meaningful communication and discussion that increase cooperation among students (Miers, 2004).

Since Google Docs' main feature is to implement collaborative writing and learning, all the students need to cooperate with each other to finish the task. As Google Docs allows users to edit and revise each other's contribution in the webpage, students of high proficiency were expected to contribute more.

\section{Significance of the study}

The findings from this research are very important, valuable and useful towards the development of the education field, especially the English language society in Malaysia. This is because, through the findings, more advantages on the implementation of CALL in language classroom can be highlighted. Other than that, the potential of Google Docs in generating better teaching and learning of writing will also enhance teachers' awareness on the 
importance of creating new teaching materials and methodologies in language classroom. Furthermore, it is hoped that ESL learners and teachers are encouraged to produce independent learning atmosphere which enhance students' active participation in the classroom. Besides, student centred learning through collaborative writing can be created to train the students to be more active, motivated as well as confident in voicing their ideas as well as opinion in the learning process. Most of all, by bringing a new classroom environment, students' interest and enthusiasm to learn to write will certainly be enhanced and developed.

Based on the researcher's point of view, it is important that teachers implement the use of Web 2.0 tools in the language classroom to enhance students' active participation during the English language lessons. This is because of the implementation of Web 2.0 tools especially the Google Docs produce students with better writing production through collaborative stages (Mak\&Coniam, 2008). Besides, it is also very useful if teachers can exploit and develop more learning activities with the integration of computer tools to enhance students' interest and motivation in the classroom better. On the other hand, for future research, it is suggested that developing the study in other context and disciplines can explain more benefits and advantages of using Google Docs for learning purpose. Besides, researchers can also investigate on how the different type of contribution in the collaboration process affect students' acquisition of language and learning skills. Finally, it is also interesting if students can provide intergroup peer feedback rather than in group collaboration as applied in this study. In a nutshell, the implementation of Google Docs for collaborative writing in language classroom brought a new teaching pedagogy which supports the development of students' proficiency in English.

\section{Acknowledgement}

The authors are very grateful to the teacher and the students of a secondary school in Malaysia for their participation in the study reported in this paper. We would also like to thank UniversitiTeknologi Malaysia and the Ministry of Education, Malaysia for granting the permission to conduct this research.

\section{References}

[1] Al-Buainain, H. (2011). Students' Writing Errors in EFL: A Case Study. QNRS Repository, 2011(1).

[2] Almala, A. H. (2006). Applying the principles of constructivism to a quality e-learning environment. Distance Learning, 3(1), 33.

[3] Aronsson, L. (2002, November). Operation of a Large Scale, General Purpose Google Docs Website.InElpub.

[4] Ashman, A., \&Gillies, R. (Eds.). (2003). Cooperative learning: The social and intellectual outcomes of learning in groups. Routledge.

[5] Bold, M. (2006). Use of Google Docs in graduate course work.Journal of Interactive Learning Research, 17(1), 5-14.

[6] Bower, M., Woo, K., Roberts, M., \& Watters, P. (2006, July). Google Docs pedagogy--a tale of two Google Docs. In 2006 7th International Conference on Information Technology Based Higher Education and Training (pp. 191-202). IEEE.

[7] Boyd, S. (2003). "Are you Ready for Social Software?" Darwin Magazine. In Gonzalez-Reinhart, J., Google Docs and the Google Docs Way: Beyond Knowledge Management Solution, Information Systems Research Center, University of Houston, TX.

[8] Bragg, A.B. (2007). Reflections on pedagogy: Reframing practice to foster informal learning with social software. Retrieved September 26, 2008 from http://matchsz.inf.elte.hu/TT/docs/Anne20Bartlett-Bragg.pdf

[9] Brown, J. D. \& Rodgers, T. S. (2003). Doing second language research. Oxford: Oxford University Press.

[10] Bruns, A., \& Humphreys, S. (2007, October). Building collaborative capacities in learners: the M/cyclopedia project revisited. In Proceedings of the 2007 international symposium on Google Docss (pp. 1-10). ACM

[11] Cress, U., \&Kimmerle, J. (2008).A systemic and cognitive view on collaborative Knowledge building with Google Docs.Computer-Supported Collaborative Learning, 3, 105-122.

[12] Deter, F., Cuthrell, K., \& Stapleton, J. (2010). Why Google Docss? student perceptions of using Google Docs in online coursework. MERLOT Journal of Online Learning and Teaching, 6(1), 122-134. Retrieved from http://jolt.merlo t.org/vol6no1/ deters_0310.pdf

[13] Faigley (1986) \& Tompkins (2008) in Li, X., Cu, K. W., \& Woo, M. (2012). Using a Google Docs-based collaborative process writing pedagogy to facilitate collaborative writing among Chinese primary school students.Australian Journal of Education Technology, 28 (1), 159-181.

[14] Faigley, L. (1986). Competing theories of process: A critique and a proposal. College English, 48(6), 527-542.

[15] Hewett (2009) in in Li, X., Cu, K. W., \& Woo, M. (2012). Using a Google Docs-based collaborative process writing pedagogy to facilitate collaborative writing among Chinese primary school students.Australian Journal of Education Technology, 28 (1), 159-181. 
[16] Hewett (2009) in Li, S., Shi, P.,\& Tang, Q. (2012) . A case study on scaffolding design for Google Docs-based collaborative writing.

[17] Hughes \& Kennedy et al, (2009).in Judd, T., Kennedy., G \& Cropper, S. (2010). Using Google Docs for collaborative learning: Assessing collaboration through contribution.Australasian Journal of Educational Technology. 26 (3), 341 354.

[18] Judd, T., Kennedy, G., \& Croppers, S. (2010). Using Google Docs for collaborative learning: Assessing collaboration through contribution. Australasian Journal of Educational Technology, 26(3), 341-354.

[19] Kim, P., Hong, J.-S., Bonk, C., \& Lim, G. (2009). Effects of group reflection variations in project based learning integrated in a Web 2.0 learning space. Interactive Learning Environments, 14 (3), 1-17.

[20] Leuf and Cunningham (2010) in Deters, F., Cuthrell, K., \& Stapleton, J. (2010). Why Google Docs? students' perceptions of using Google Docs in online coursework. MERLOT Journal of Online Learning and Teaching, 6(1), 122-134. Retrieved from http://jolt.merl ot.org/vol6no1/deters_0310.pdf

[21] Leuf, B. \& Cunningham, W. (2001).The Google Docs way: Quick collaboration on the Web. Upper Saddle River, NJ: Addison Wesley.

[22] Leung, K., \& Chu, S. K. W. (2009).Using Google Docs for collaborative learning: A case study of an undergraduate students' group project in Hong Kong.http://ww w.ickm2009.org/snews/upload/ickm 2009.

[23] Li, X., Cu, K. W., \& Woo, M. (2012). Using a Google Docs-based collaborative process writing pedagogy to facilitate collaborative writing among Chinese primary school students.Australian Journal of Education Technology, 28 (1), 159181.

[24] Mak, B., \&Coniam, D. (2008). Using Google Docs to enhance and develop writing skills among secondary school students in Hong Kong. System, 36, 437-455.

[25] Miers, J. (2004). BELTS or Braces?Technology School of the Future. Retrieved from http://www.tsof.edu.au/research/Reports04/miers.asp

[26] Morgan, B., \& Smith, R. D. (2008). Technology in Literacy Education: A Wiki for Classroom Writing. The Reading Teacher, (62) 80-82. Retrieved from http://www.jstor.org/stable/20204663.

[27] Nagin, C. (2003). National Writing Project. Because Writing Matters: Improving Student Writing in Our Schools.

[28] NazatulshimaMustafar. (2006, April). The use of computer assisted language learning (call) courseware in learning literature: A case study of form four student of SekolahMenengahDato' PenggawaBarat, Pontian, JohorDarulTakzim. website: http:// www.fp.utm.my/e PusatSumber /pdffail/ptkghdfwP/NAZATULSHI MAAP010249D2006TTP.pdf

[29] O'Neill, M.E. (2005). Automated use of a Google Docs for collaborative lecture notes. Proceedings of the 36th SIGCSE Technical Symposium on Computer Science Education, St. Louis, Missouri, USA: February 23-27, $267-271$. Retrieved from http://portal.acm.org/citation.cfm?id=1047440

[30] Robinson, M. (2006).Google Docs in education: Social construction as learning. The Community College Enterprise, 107-109.

[31] Ryan, R. (2007). The Effects of Web-Based Social Networks on Student Achievement and Perception of Collaboration at the Middle School Level.Ph.D. dissertation, Touro University International, California.

[32] Scardamalia, M., \&Bereiter, M. W. (2006). Knowledge building: Theory, pedagogy, and technology in K. Sawyer (Ed.), Cambridge handbook of the learning sciences (pp. 97-118). New York: Cambridge University Press.

[33] Tompkins (2008), in Li, S., Shi, P.,\& Tang, Q. (2012). A case study on scaffolding design for Google Docs-based collaborative writing.

[34] Trentin, G. (2009). Using a Google Docs to evaluate individual contribution to a collaborative learning project.Journal of Computers Assisted Learning, 25, 43-55.

[35] Violet, S., \& Mansfield, C. (2006). Group work at university: Significance of personal goals in the strategies of students with positive and negative appraisals. Higher Education Research \&Development, 25 (4), 341-356.

[36] Vygotsky, L. (1978). Interaction between learning and development. Readings on the development of children, 23(3), 34-41.

[37] William, M., \& Burden, R. L. (1997).Psychology for language teachers. Cambridge: Cambridge.

[38] Winkler, A. C., \&McCuen, J. R. (1997).Grammar Talk. Prentice Hall..

[39] Witts (2011) in Li, X., Cu, K. W., \& Woo, M. (2012). Using a Google Docs-based collaborative process writing pedagogy to facilitate collaborative writing among Chinese primary school students.Australian Journal of Education Technology, 28 (1), 168-181.

[40] Wood, D., Bruner, J. S., \& Ross, G. (1976).The role of tutoring in problem solving. Journal of child psychology and psychiatry, 17(2), 89-100. 